\title{
Cálculo de área de triângulos quaisquer: uma proposta a partir de práticas laborais
}

\author{
Ieda Maria Giongo \\ Professora, UNIVATES/RS \\ igiongo@univates.br
}

\section{Márcia Jussara Hepp Rehfeldt \\ Professora, UNIVATES/RS \\ mrehfeld@univates.br}

\section{Marli Teresinha Quartieri}

Professora, UNIVATES/RS

mtquartieri@univates.br

\section{Stephanie Cristine Hepp Rehfeldt}

Bolsista de IC/FAPERGS

srehfeldt@universo.univates.br

\begin{abstract}
Resumo
A presente sugestão de atividade para sala de aula é oriunda das práticas laborais de engenheiros civis e tem por objetivo apresentar dois problemas, envolvendo cálculo de área de triângulos quaisquer que sugerem o uso da lei dos senos, dos cossenos e do cálculo de área de triângulo qualquer. As atividades são descritas antes de cada figura e sua metodologia é sugerida. Ao acabá-las, propõe-se uma visita ao escritório de um engenheiro ou arquiteto para fins de avaliação das práticas laborais. Com isso, espera-se contribuir com os processos de ensino e de aprendizagem da Matemática, em especial, no que concerne ao estudo da trigonometria no triângulo qualquer.
\end{abstract}

Palavras-chave: Trigonometria. Triângulo qualquer. Prática laboral.

\section{Area calculation in arbitrary triangles: a teaching proposal from engineering work}

\begin{abstract}
This proposal for classroom activity arises from civil engineering work and aims at presenting two problems involving the area calculation of arbitrary triangles that suggest the use of the Sine, Cosine Rule and the area calculation of an arbitrary triangle. The activities are described before each figure and their methodology is suggested. When activities have been finished, a visit to an engineer or architect's office is proposed, in order to evaluate the practice. Thereby, a contribution to the math teaching and learning processes is expected, especially, concerning the study of the arbitrary triangle in trigonometry.
\end{abstract}

Keywords: Trigonometry. Arbitrary triangle. Work practice. 


\section{Uma reflexão inicial}

Estudos como os de Rehfeldt et al. (2011) mostram que o ensino e a aprendizagem da trigonometria no triângulo qualquer é pouco significativo no Ensino Médio. Esse foi um dos assuntos que os alunos menos lembraram no momento em que realizaram uma prova de nivelamento de Matemática ao ingressarem na disciplina de Cálculo I dos cursos de Engenharia da Instituição. Acredita-se que tal fato tenha relação com o material proposto pelo professor que, muitas vezes, não apresenta aplicabilidade. Huanca (2006, p. 99), pesquisando a opinião de docentes acerca do ensino da trigonometria, aponta:

Apesar dessa importância, eles [os professores] afirmam que os livros didáticos, para o Ensino Médio, dedicam muitas páginas ao ensino de trigonometria, não deixando claro, nem para o aluno, nem para o professor, para que serve este abundante material trabalhado. [...] O tema Trigonometria vem ocupando lugar de destaque no currículo das disciplinas de Matemática nas escolas de Ensino Médio e Superior.

$\mathrm{O}$ autor ainda complementa afirmando que "[...] pesquisas apontam que o mesmo é apresentado de maneira alienada das situações cotidianas e, além disso, é estudado através de fórmulas que os alunos usam sem produzir o menor significado a respeito delas" (HUANCA, 2006, p. 99). No entanto, o tema trigonometria está explícito nos Parâmetros Curriculares do Ensino Médio ( $\left.\mathrm{PCN}_{+} \mathrm{EM}\right)$, os quais sugerem que o trabalho pode ser desenvolvido com triângulos retângulos e triângulos quaisquer. Ademais, o documento expressa:

[...] ao se perceber a origem [...] das razões trigonométricas como resultado do avanço tecnológico do período das grandes navegações do século 16, pode-se conceber a Matemática como instrumento para a solução de problemas práticos e que se desenvolve para muito além deles, ganhando a dimensão de ideias gerais para novas aplicações fora do contexto que deu origem a elas (BRASIL, 1998, p. 115).

Tomando como pressuposto a necessidade de contemplar os $\mathrm{PCN}_{+} \mathrm{EM}$ (BRASIL, 1998) e os resultados de algumas pesquisas, apresentam-se, a seguir, algumas atividades para o ensino da trigonometria em triângulos quaisquer. Sugere-se que estas sejam realizadas após os alunos tomarem conhecimento das fórmulas trigonométricas relacionadas ao triângulo qualquer: lei dos senos, lei dos cossenos e cálculo de área. 


\section{As atividades propostas}

A geração desse material como sugestão de sala de aula originou-se após entrevista com dois engenheiros, membros da comunidade do Vale do Taquari, Região Central do Rio Grande do Sul. Ambos relataram que, no cotidiano, encontram situações que requerem conhecimentos acerca da trigonometria, em especial, para calcular área de triângulos quaisquer. Embora façam uso do software $\mathrm{CAD}^{1}$, ressaltaram que é importante revisar os cálculos por meio de fórmulas trigonométricas.

Nesse contexto, propomos duas atividades. Como primeiro desafio, os discentes receberiam a figura 1, ilustrada a seguir e extraída de uma situação real de um dos engenheiros entrevistados, para o cálculo de sua área, porém sem as linhas tracejadas. Essa atividade pode ser realizada em grupos de 3 a 4 alunos. $\mathrm{O}$ professor poderá iniciar o desafio com perguntas sobre as diferentes possibilidades de divisão desta figura em triângulos, bem como uma análise dos elementos disponíveis (lados e ângulos) em cada nova figura que se forma. Além disso, espera-se que o docente peça aos estudantes quais as fórmulas que podem ser aplicadas em cada figura em função desses elementos disponíveis. Caso eles tenham dúvidas, nossa sugestão de sequência de cálculo está representada pelas linhas tracejadas e ordem de numeração dos triângulos.

Para realizar essa tarefa, são necessárias aplicações da lei dos senos e dos cossenos e ainda da fórmula do cálculo de área num triângulo qualquer. $\mathrm{O}$ uso de calculadora científica é imprescindível. Observa-se, ainda, que alguns ângulos apresentam medidas em graus e minutos. Por isso, recomenda-se ao professor problematizar com os alunos a conversão de graus em minutos e vice-versa. Ao término da atividade e como forma de conferência do cálculo da área, pode-se estimar o valor dela, sobrepondo um retângulo. Ressaltamos a importância de o docente realizar, inicialmente, a estimativa do valor da área.

1. Computer Aided Design - CAD é um software utilizado no auxílio à criação, à modificação, à análise e à otimização de um projeto. 


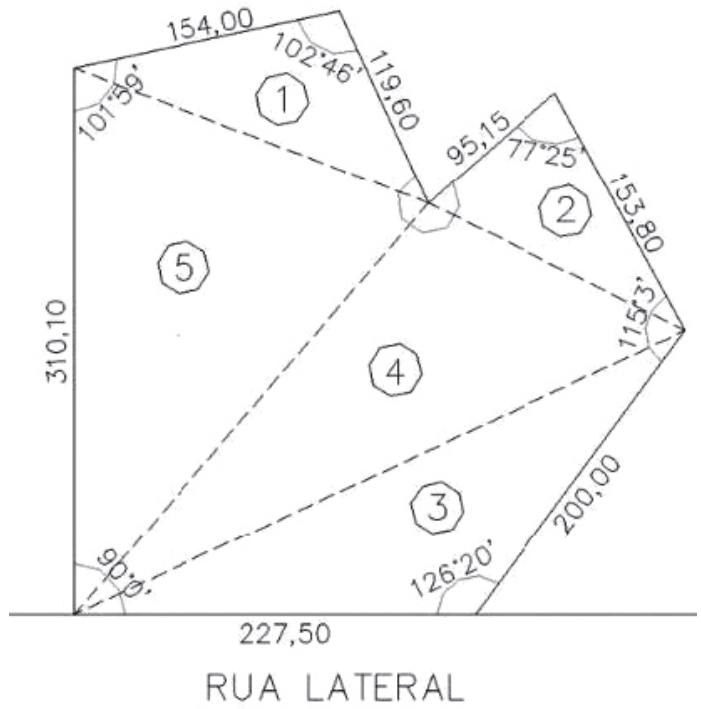

Figura 1 - área de terra localizada em uma comunidade do Vale do Taquari.

Fonte: engenheiro entrevistado.

A resposta esperada para essa atividade seria uma área de $89795,42 \mathrm{~m}^{2}$.

A segunda atividade a ser proposta trata-se de uma divisão de um lote de terra (cedida por um dos engenheiros entrevistados) representado na figura 2 . $\mathrm{O}$ pressuposto inicial consistia no fato de que cada uma das partes tivesse a mesma área. As duas famílias envolvidas na partilha da maior já haviam acordado que uma ficaria com a parte de terra com frente de $400 \mathrm{~m}$ para a rua e a outra com os $97 \mathrm{~m}$ restantes. As laterais dos dois terrenos medem $171 \mathrm{~m}$ e $428 \mathrm{~m}$, respectivamente. A dúvida que se tinha era: em qual ponto, sobre o lado de 171 metros, a linha divisória deveria tocar?

Assim, a tarefa a ser realizada é a seguinte: dividir a área de terra maior em duas partes conforme indicado pela linha pontilhada, de tal forma que elas tenham a mesma área. Da mesma maneira que o problema anterior, a turma pode ser dividida em grupos. Indicamos que se problematize com os alunos qual o primeiro cálculo a ser realizado. Sugerimos que se inicie pelo dos ângulos internos do triângulo maior, usando a lei dos senos. A seguir, é possível calcular a área total da figura. Na sequência, pode-se empregar a fórmula da área de triângulos quaisquer e encontrar o tamanho do lado do triângulo menor, ou seja, o que realmente o problema deseja saber. 


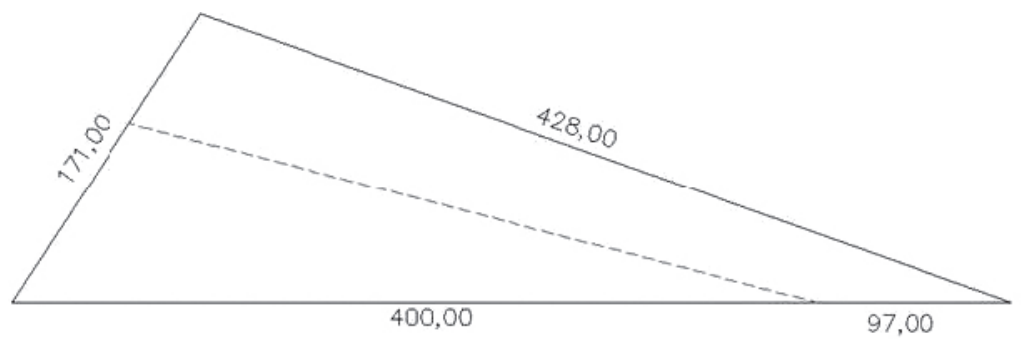

Figura 2 - área de terra localizada em uma comunidade do Vale do Taquari.

Fonte: engenheiro entrevistado.

A resposta esperada para essa segunda atividade seria que o lado de $171 \mathrm{~m}$ é cortado pela linha pontilhada aos $106,2355 \mathrm{~m}$.

Outra tarefa proposta para o estudo da trigonometria em triângulos quaisquer consiste em que o professor visite com seus alunos um escritório de engenharia ou de arquitetura para conhecer o quanto o cálculo de área de triângulo qualquer faz parte das atividades laborais desses profissionais. Ainda, poder-se-ia privilegiar um debate no retorno à sala de aula, bem como um relatório escrito acerca do tema.

Entende-se que a realização dessas atividades possa auxiliar no desenvolvimento da percepção da aplicabilidade da matemática, favorecer uma prática da pesquisa, motivar o aluno, fazê-lo perceber a relação da matemática com outros componentes curriculares e colaborar na compreensão do papel sociocultural da

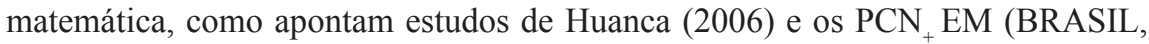
1998). Ademais, o desenvolvimento de tais atividades pode contribuir para uma aprendizagem significativa da trigonometria no triângulo qualquer, uma vez que é um dos assuntos menos lembrados pelos estudantes quando estes realizam provas de nivelamento como mostram os estudos de Rehfeldt et al. (2011).

\section{Referências}

BRASIL, PCN+ Ensino Médio. Orientações Educacionais Complementares aos Parâmetros Curriculares Nacionais. Ciências da Natureza. Matemática e suas Tecnologia, 1998. Disponível em: < http://portal.mec.gov.br/seb/arquivos/pdf/CienciasNatureza. pdf $>$. Acesso em: 20 de maio de 2012.

\section{HUANCA, R. R. H. A resolução de problemas no processo ensino-aprendizagem-} -avaliação de matemática na e além da sala de aula. 2006. 253 f. Dissertação (Mestrado) - Programa de Pós-Graduação em Matemática, Instituto de Geociências 
e Ciências Exatas, Universidade Estadual Paulista, Rio Claro, 2006. Disponível em: <http://www.athena.biblioteca.unesp.br/exlibris/bd/brc/33004137031P7/2006/ huamanhuanca_rr_me_rcla.pdf $>$ Acesso em: 10 de maio de 2012.

REHFELDT ET AL. Dificuldades apresentadas pelos alunos nas provas de nivelamento de Cálculo I e as implicações na Escola Básica. In: SEMINÁRIO INSTITUCIONAL DO PIBID UNIVATES, 1, 2011. Lajeado. Anais... Porto Alegre: Evangraf, 2011, p. 36-38.

Submetido em maio de 2012 Aprovado em setembro de 2012 